\title{
A Self-aligned Structure AlGaAs/GaAs HBT's Using Silicon Nitride Sidewall Technique
}

\author{
Bei Ping Yan, Edward S Yang \\ Department of Electrical \& Electronic Engineering \\ The University of Hong Kong \\ Pokfulam Road, Hong Kong \\ Email address: bpyan@eee.hku.hk \\ Suggested area: Compound Semiconductor Devices and Technology
}

\begin{abstract}
A self-aligned fabrication process for $\mathrm{AlGaAs} / \mathrm{GaAs}$ heterojunction bipolar transistors (HBT's) is presented. The advantage of this process is that selfaligned structure and device passivation can be realized simultaneously using silicon nitride sidewall technique. The silicon nitride sidewall functions both as an isolation layer to prevent shorting between the base metal and the emitter mesa and as an etching mask to prevent AlGaAs passivation layer to be removed. $A$ current gain cutoff frequency $f_{T}$ of $30 \mathrm{GHz}$ and a maximum oscillation frequency $f_{\max }$ of $50 \mathrm{GHz}$ have been obtained from the device with $3 \mu \mathrm{m} \times 15 \mu \mathrm{m}$ emitter size.
\end{abstract}

\section{Introduction}

$\mathrm{AlGaAs} / \mathrm{GaAs}$ heterojunction bipolar transistors(HBT's) are very attractive devices for high-speed digital circuit and microwave power applications. This is because AlGaAs/GaAs HBT's possess many inherent advantages, such as very short transit time[1], high current handling capacity[2], large transconductance exponentially dependent on Vbe[3], clean pinch off in the off cycle[3], and controllable breakdown voltage with collector epitaxial design[4]. Using these advantages, excellent $\mathrm{RF}$ performance have been demonstrated [5-6]. In order to reach high speed and excellent microwave performance, many self-aligned schemes have been presented to reduce base resistance and parasitic capacitance, as well as intrinsic transit time. However, the device passivation is also a very important issue related to the device reliability. In this paper, a self-aligned fabrication process for AlGaAs/GaAs HBT's is presented. The advantage of this process is that self-aligned structure and device passivation can be realized simultaneously using silicon nitride sidewall technique. A current gain cutoff frequency $f_{T}$ of $30 \mathrm{GHz}$ and a maximum oscillation frequency $f_{\max }$ of more than $50 \mathrm{GHz}$ have been achieved from the device with $3 \mu \mathrm{m} \times 15 \mu \mathrm{m}$ emitter size.

\section{Device Fabrication}

The epitaxial device structure was grown on 3-inch-diameter semi-insulating GaAs substrates using MOCVD technique. The material structure is shown in Table. 1.

Table 1

The HBT epitaxial layer structure

\begin{tabular}{llll}
\hline Layer & $\mathrm{x}$ & $\begin{array}{l}\text { Doping } \\
\left(/ \mathrm{cm}^{3}\right)\end{array}$ & $\begin{array}{l}\text { Thickness } \\
(\mathrm{A})\end{array}$ \\
\hline $\mathrm{n}+-\mathrm{In}_{\mathrm{x}} \mathrm{Ga}_{1-\mathrm{x}} \mathrm{As}$ & 0.15 & $1 \times 10^{19}$ & 200 \\
$\mathrm{n}^{+}-\mathrm{GaAs}$ & & $5 \times 10^{18}$ & 800 \\
$\mathrm{n}^{-}-\mathrm{Al}_{\mathrm{x}} \mathrm{Ga}_{1-\mathrm{x}} \mathrm{As}$ & $0.3-0$ & $5 \times 10^{17}$ & 300 \\
$\mathrm{n}^{-}-\mathrm{Al}_{\mathrm{x}} \mathrm{Ga}_{1-\mathrm{x}} \mathrm{As}$ & 0.3 & $5 \times 10^{17}$ & 1200 \\
$\mathrm{n}^{-}-\mathrm{Al}_{\mathrm{x}} \mathrm{Ga}_{1-\mathrm{x}} \mathrm{As}$ & $0-0.3$ & $5 \times 10^{17}$ & 300 \\
$\mathrm{p}^{+}-\mathrm{GaAs}$ & & $4 \times 10^{19}$ & 1000 \\
$\mathrm{n}^{-}-\mathrm{GaAs}$ & & $5 \times 10^{16}$ & 5000 \\
$\mathrm{n}^{+}-\mathrm{GaAs}$ & & $4.5 \times 10^{18}$ & 6000 \\
S. I. Substrate & & & \\
\hline
\end{tabular}


The emitter -base graded junction was adopted. The thickness and doping level of the heavily C-doped base were $100 \mathrm{~nm}$ and $4 \times 10^{19} \mathrm{~cm}^{-3}$, respectively. The collector was designed to give the base-collector breakdown voltage higher than $17 \mathrm{~V}$ without increasing collector transit time too much.

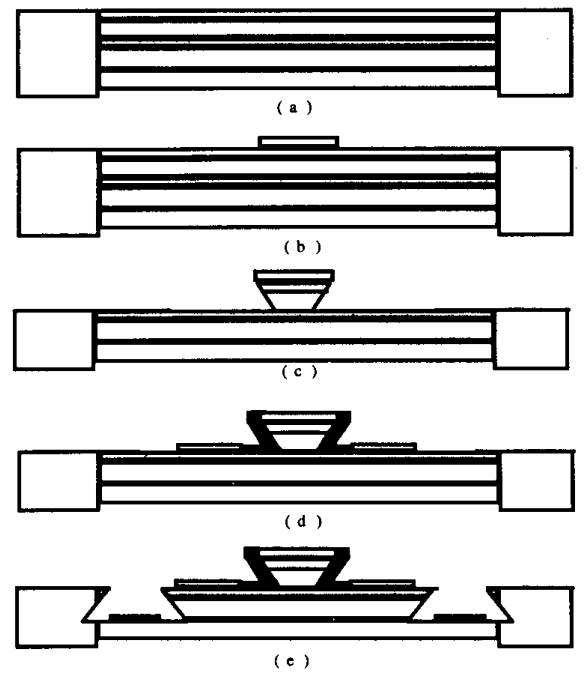

Fig. 1 The process sequence for self-aligned HBT (a) proton implantation (b) emitter contact formation (c) etch down to base and form nitride sidewall (d) base contacts formation (e) etch subcollector and form collector contacts

The process sequence is shown in Fig. 1. Device fabrication begins with a proton implantation to isolate the active device region defined by the isolation mask. The masking material for implantation consists of $1150 \AA$ of silicon nitride deposited by Plasma Enhanced Chemical Vapor Deposition (PECVD) plus $6 \mu \mathrm{m}$ of photoresist AZ 4620. The proton implantation is done with a dose of $2 \times 10^{15} / \mathrm{cm}^{2}$ at $200 \mathrm{KeV}$, followed by a dose of $1 \times 10^{15} / \mathrm{cm}^{2}$ at $120 \mathrm{KeV}$ and $1 \times 10^{15} / \mathrm{cm}^{2}$ at $30 \mathrm{KeV}$, respectively. The substrates are misaligned during implantation to avoid channeling.
After implantation, the masking materials of photoresist and silicon nitride are removed by acetone and buffered $\mathrm{HF}$ acid. An $\mathrm{Au} / \mathrm{Ge} / \mathrm{Ni} / \mathrm{Au}$ metal layer is then evaporated and selectively lifted off using the emitter mask. The metal emitter contacts are subsequently used as a natural mask to wet-etch the regions other than the emitter mesas down to approximately $500 \AA$ above the $\mathrm{p}^{+}$base layer. The etching process includes an initial etch of 3:1:50 $\mathrm{H}_{3} \mathrm{PO}_{4}: \mathrm{H}_{2} \mathrm{O}_{2}: \mathrm{H}_{2} \mathrm{O}$ solution to remove the top InGaAs cap layer, followed by a 10:4:500 NH4OH: $\mathrm{H}_{2} \mathrm{O}_{2}: \mathrm{H}_{2} \mathrm{O}$ solution to etch down to approximately $500 \AA$ above the $\mathrm{p}^{+}$base layer. After this etching step, around $500 \AA \mathrm{AlGaAs}$ emitter layer is exposed to air. This layer is, to a first approximation, fully depleted due to the combination of surface Fermi level pinning on the top and being the more lightly doped layer in the base-emitter junction below. After that, a layer of silicon nitride is then deposited by PECVD. The nitride is then etched by RIE, leaving only sidewall silicon nitride covering the sides of the emitter mesas and external base surface under the emitter metal. Next, 10:4:500 NH4OH: $\mathrm{H}_{2} \mathrm{O}_{2}: \mathrm{H}_{2} \mathrm{O}$ solution is used again to etch down to the base. Because the AlGaAs surface under emitter metal is covered by silicon nitride, this etching step does not remove the depleted AlGaAs layer under emitter metal. The base contact region is subsequently defined and a base contact metal of $\mathrm{Ti} / \mathrm{Pt} / \mathrm{Au}$ is e-beam evaporated and lifted off. The base is self-aligned to the emitter, and the nitride sidewall functions both as an isolation layer to prevent shorting between the base metal and the emitter mesa and as a etching mask to prevent AlGaAs passivation layer to be removed. In this way, we both realize the self-aligned structure HBT's and complete the device passivation 
simultaneously. The device active region is then defined with base island mask. The area outside this masked region is etched down well into the subcollector layer. The collector is then defined and contact metal of $\mathrm{Au} / \mathrm{Ge} / \mathrm{Ni} / \mathrm{Au}$ is used. The contact is alloyed at $410 \mathrm{C}$ for $10 \mathrm{~s}$. Finally, interconnect metal $\mathrm{Ti} / \mathrm{Au}$ is applied to contact the different electrodes. The SEM photograph of the final device fabricated is shown in Fig. 2.

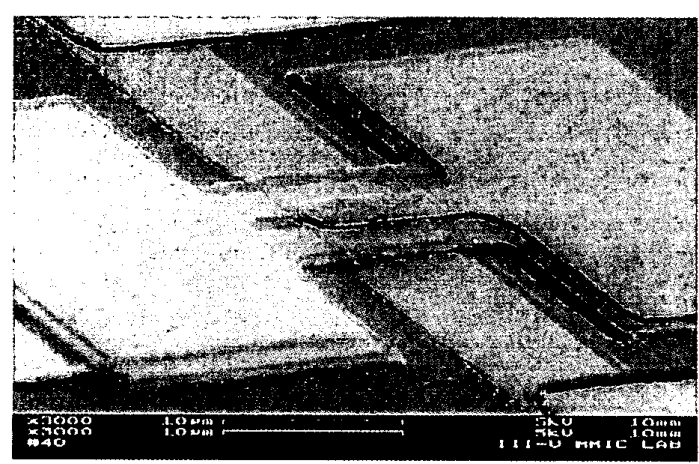

Fig. 2 The SEM photograph of the self-aligned HBT with sidewall technique

\section{Device Performance and Discussions}

The device dc characteristics were measured by directly probing on the wafer using HP4155 parameter analyzer.

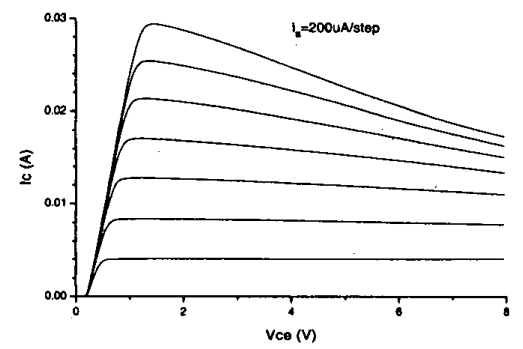

$\mathrm{I}_{\mathrm{C}}-\mathrm{V}_{\mathrm{CE}}$ characteristics of self-aligned HBT

Fig. 3

Fig. 3 shows the dc common-emitter $\mathrm{I}_{\mathrm{C}^{-}}$ $\mathrm{V}_{\mathrm{CE}}$ characteristics of single-finger HBT fabricated by sidewall technique. The area of the device is $3 \times 15 \mu \mathrm{m}^{2}$. As can be seen from Fig. 3, device shows excellent dc performance. The current gain is more than 20 and offset voltage is about $200 \mathrm{mV}$. The knee voltage is about $1 \mathrm{~V}$ at collector current of $30 \mathrm{~mA}$. The negative slope in I-V curve is caused by device self-heat, which will give rise to the current gain decrease.

Fig. 4 shows the Gummel plot of the device. It can be seen from fig. 4 that the junction performance is good and the leakage current is small.

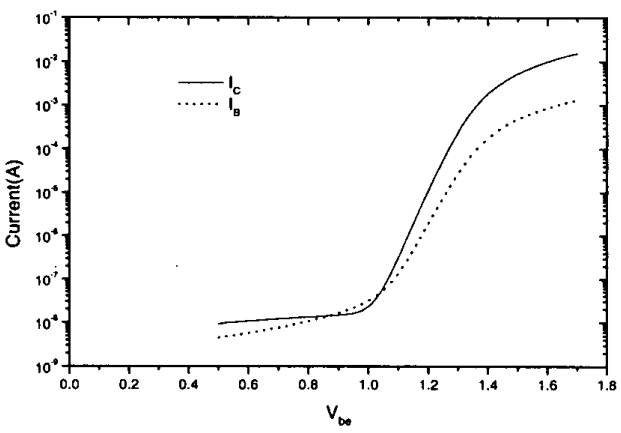

Fig. 4 The Gummel plot of the self-aligned HBT

Fig. 5 shows the RF performance of the device. It demonstrates a current gain cutoff frequency $f_{T}$ of $30 \mathrm{GHz}$ and a maximum oscillation frequency $f_{\max }$ of more than $50 \mathrm{GHz}$.

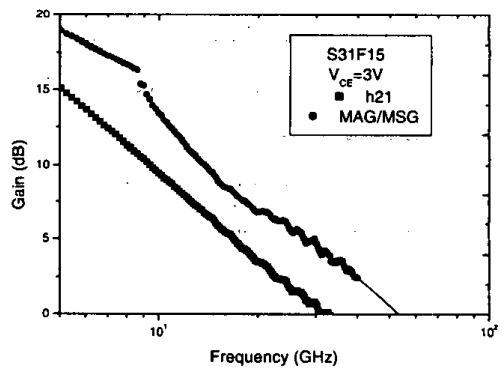

Fig. 5 Microwave performance of self-aligned HBT

\section{Conclusion}

A self-aligned fabrication process for AlGaAs/GaAs HBT's is presented. The advantage of this process is that selfaligned structure and device passivation 
advantage of this process is that selfaligned structure and device passivation can be realized simultaneously using silicon nitride sidewall technique. The silicon nitride sidewall functions both as an isolation layer to prevent shorting between the base metal and the emitter mesa and as a etching mask to prevent AlGaAs passivation layer to be removed. In this way, we both realize the selfaligned structure HBT's and complete the device passivation simultaneously.

\section{References}

[1] T. Ishibashi, et al., IEEE Trans. Electron Devices, vol. 35, no.4, pp401-404, 1988.

[2] B. Bayraktaroglu, et al., IEEE Trans. Electron'Device Lett., vol. 14, no. 10, pp.493-495, 1993

[3] N. L. Wang et al., IEEE Trans. Microwave Theory Tech., vol. 38, no.10, pp1381-1389, 1990

[4] J. J. Chen et al., IEEE Trans. Electron Devices, vol. 36, no. 10, pp.21652172, 1989

[5] P. K. Ikalainen et al., in IEEE MTT-S Int. Microwave Symp. Dig., 1994, pp. 679-682.

[6] T. Shimura et al., IEEE Trans. Electron Device, vol. 42, no. 11, pp.18901895, 1995 